\title{
Host Kairomones Elicit Area-Restricted Search by Prorops nasuta, A Parasitoid of the Coffee Berry Borer
}

\author{
Pilar Chiu-Alvarado, Antonio Santiesteban, and Julio C. Rojas* \\ Departamento de Entomología Tropical, El Colegio de la Frontera Sur (ECOSUR), Tapachula, Chiapas, Mexico
}

\begin{abstract}
The bethylid wasp Prorops nasuta Waterston is a natural enemy of the coffee berry borer, Hypothenemus hampei Ferrari, the most devastating insect pest of coffee worldwide. Volatiles from H. hampei immature stages and dust/frass are used by $P$. nasuta as long-range cues during the host location process. In addition, host dust/frass extracts influenced the area-restricted search by $P$. nasuta females. In this study, we evaluated the effect of organic solvent extracts from $H$. hampei immature stages and adults on several parameters regarding locomotory behavior of $P$. nasuta females. $P$. nasuta females spent more time, covered greater distance, reduced their speed, and turned more per unit time in patches treated with hexanic, acetonic, and methanolic extracts from $H$. hampei immature stages and adults with respect to the solvent controls. The concentration of the methanolic extract from $H$. hampei immature stages clearly influenced the locomotory activity of $P$. nasuta.
\end{abstract}

Keywords: Host location, contact chemicals, kairomones, arrestment, bethylid, Hypothenemus hampei.

\section{INTRODUCTION}

The bethylid wasp Prorops nasuta Waterston is a natural enemy of the beetle Hypothenemus hampei (Ferrari), the most devastating insect pest of coffee worldwide. Female wasps feed on several eggs, larvae, and pupae before laying eggs on host pre-pupae and pupae where the hatching larvae develop as ecto-parasitoids. This parasitoid species has been widely introduced to Latin America as a biological control agent against $H$. hampei [1]. Currently, $P$. nasuta and other $H$. hampei parasitoids are used in an integrated pest management program in combination with entomopathogenic fungi, traps baited with a methanol: ethanol blend, and harvesting of mature coffee berries to eliminate $H$. hampei habitat [2].

Parasitoids search for hosts that are dispersed in time and space; consequently the process of host location is a major obstacle to the reproductive success of any species. Locating potential hosts for laying is a critical challenge in the life of many parasitoids [3]. The mechanisms a parasitoid uses to locate its host can be expected to significantly influence its searching capacity, an important parameter of parasitoid effectiveness. Parasitoid females assess host presence and acceptability on the basis of olfactory, visual and tactile cues [4]. Previous studies have shown that the host location behavior of $P$. nasuta is mediated by chemical cues from dust/frass of $H$. hampei [5, 6].

In this study, we evaluated the effect of organic solvent extracts from $H$. hampei immature stages and adults on several parameters of the locomotory behavior of $P$. nasuta females.

\footnotetext{
*Address correspondence to this author at the Departamento de Entomología Tropical, El Colegio de la Frontera Sur (ECOSUR), Carretera Antiguo Aeropuerto km 2.5, Tapachula, Chiapas, Mexico; Tel: (942) 6289800; Fax: (962) 6289806; E-mail: jrojas@ecosur.mx
}

\section{MATERIALS AND METHODS}

\section{Biological Material}

Parasitoids used in this study were reared on H. hampei as described elsewhere [5,6]. The parasitoid culture was maintained under a 12: $12 \mathrm{~h}$ (light:dark) photoperiod, temperature regimen ranging from $18-30{ }^{\circ} \mathrm{C}$, and relative humidity from $60-85 \%$. Newly emerged, unfed and presumed mated 1-2 day old females were used in all experiments. Individuals used in this study cannot be considered naive because before emerging from the cultures, they had been in contact with coffee berries and host remains [7]. They were collected and kept in plastic containers $(15.5 \times 9 \times 6.5 \mathrm{~cm})$ until being tested.

Hypothenemus hampei immature stages (pre-pupae, pupae) and adults were obtained from infested ripe coffee berries, collected regularly in coffee plantations near Tapachula, Chiapas, Mexico. Non-parasitized coffee berry borer individuals were used for preparing the extracts.

\section{Bioassays}

The bioassays were conducted in a $9.0 \mathrm{~cm}$ diameter glass Petri dish, which was fitted with a filter paper disc (Whatman, No. 1, Whatman, Brentford, UK) at the bottom of dish $[6,7]$. A circular area $3 \mathrm{~cm}$ in diameter was lightly drawn with a pencil in the centre of the filter paper. The chosen extract was applied to the midpoint of this circular zone using a Hamilton ${ }^{\circledR}$ Syringe (Hamilton Company, Reno, NV, USA). Drops of the extract were applied until the solvent front roughly reached the edge of the marked zone or patch. Pure solvent (hexane, acetone or methanol) was used as a control. After $40 \mathrm{~min}$, once the solvent had evaporated, one parasitoid was introduced into the centre of the treated zone. Observation commenced when a parasitoid began walking on the treated zone and ended when the wasp left it or flew away. The insects were observed for 5 min and tested once. 
Residence time in patch (s), total distance moved (cm), mean velocity $\left(\mathrm{cm} \mathrm{s}^{-1}\right)$, mean absolute angular velocity (unsigned degrees $\mathrm{s}^{-1}$ ), and mean absolute meander (unsigned degrees $\mathrm{cm}$ ) were recorded by using Ethovision software v 1.95 (Noldus Information Technology, Leesburg, VA). All tests within a group of experiments were carried out on the same day, using six parasitoids per treatment per day and tests were repeated on consecutive days, until completing the total number of 30 females. All bioassays were performed in an environmentally controlled room between 10:00 and 15:00 h, at $26-28{ }^{\circ} \mathrm{C}$ and relative humidity of $60-70 \%$.

\section{Influence of Organic Solvent Extracts on the Locomotory Behavior of Female Parasitoids}

In this experiment, we evaluated what type of solvents could extract the chemical cues from $H$. hampei immature stages and adults that influence locomotory behavior of $P$. nasuta. The extracts were prepared by dipping either $20 \mathrm{mg}$ of immature stages (prepupae and pupae) or $20 \mathrm{mg}$ of adults, for $1 \mathrm{~min}$ in $2 \mathrm{ml}$ hexane (95\% purity, HPLC grade, Aldrich), acetone (99.6\% purity, HPLC, grade J.T. Baker) or methanol (99.9\% purity, HPLC grade, J. T. Baker). Bioassays were performed with crude extracts and tested in the experimental arena described bellow. Five hundred microlitres of each extract (hexane, acetone or methanol) was applied onto the filter paper and each extract was tested in a random order.

\section{Influence of Extract Concentration on the Locomotory Behavior of Parasitoid Females}

In this experiment, we tested the influence of methanolic extract concentration of $H$. hampei immature stages on the locomotory behavior of $P$. nasuta females. An immature stage methanol extract was evaporated at room conditions and concentrated at the following concentrations: $0,0.5,1$, $1.5,3$, and $6 \mathrm{mg}$ immature stages per $100 \mu 1$ of solvent. One hundred microlitres of each concentration was tested in the bioassays; each concentration was evaluated in a random order.

\section{Statistics}

Data were analyzed using the Statistica Software Program (release 6.1, StatSoft, Inc.). Data were $\ln$ transformed and then analyzed by one-way analysis of variances (ANOVA). Significant differences were separated by Tukey HSD test.

\section{RESULTS}

\section{Behavior of $\boldsymbol{P}$. Nasuta in Response to Host Extracts}

When parasitoids contacted the centre of the patch treated with host extracts, they briefly decreased their walking speed, drummed the patch with their antennae and touched it with their front tarsi, alternating between movements and resting periods. They also frequently moved their wings however; they did not attempt to fly. The parasitoids generally walked in a straight path across a control patch. Typical tracks of $P$. nasuta females in response to different extracts and controls are shown in Fig. (1).

\section{Influence of Organic Solvent Extracts on the Locomotory Behavior of Female Parasitoids}

When hexane, acetone and methanol were used for extraction, $P$. nasuta females spent more time, covered a greater distance and turned more per unit time in patches treated with extracts from immature stages and adults of $H$. hampei with respect to the solvent controls. Parasitoids reduced their
Hexane

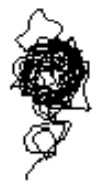

Acetone
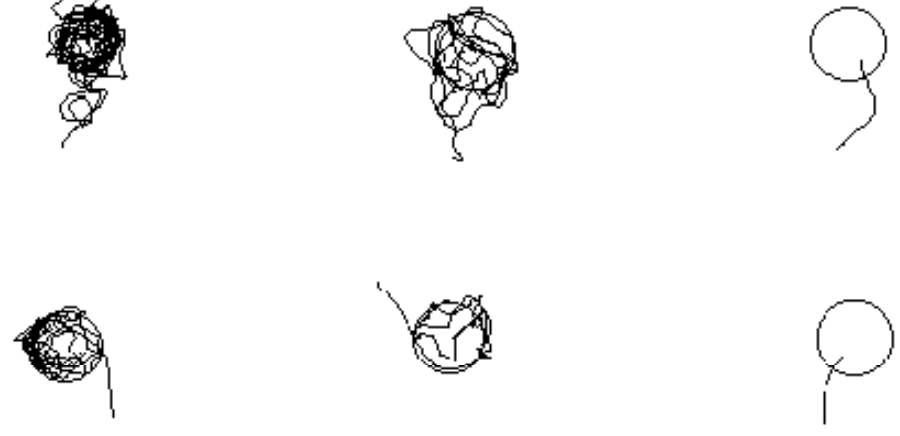

Methanol
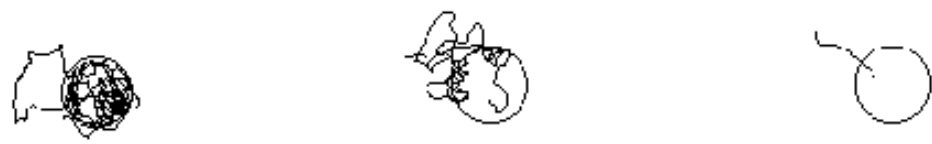

Adults

\section{Control}

Fig. (1). Typical examples of recorded tracks of $P$. nasuta females in an experimental arena ( $9 \mathrm{~cm}$ diameter, inner circle, $3 \mathrm{~cm}$ diameter) over a 5 min run. Zones treated with hexane, acetone, or methanol extracts from immature stages and adults of $H$. hampei and solvent controls. 
speed when contacting patches containing the extracts of immatures compared with those treated with extracts of adults and solvent controls. The extracts of immatures and adults affected the meander in comparison to controls (Tables $\mathbf{1}, \mathbf{2}$, and $\mathbf{3}$ ).

\section{Influence of Extract Concentration on the Locomotory Behavior of Parasitoid Females}

The concentration of the methanolic extract from $H$. hampei immature stages influenced the locomotory activity of $P$. nasuta $(\mathrm{F}=8.62 ; \mathrm{df}=5,180 ; \mathrm{P}<0.001)$. Parasitoid females spent more time on patches treated with 1, 1.5, 3 and $6 \mathrm{mg}$ of immature stage extract than patches treated with methanol. There was no difference in the time that females spent on patches treated with $0.5 \mathrm{mg}$ immature stage extract and those treated with $1,1.5,3$, and $6 \mathrm{mg}$ of host material, and control (Fig. 2).

\section{DISCUSSION}

The role of chemical cues in long and short-range host searching behavior has been studied in a few bethylid species. Previously, we have shown that $P$. nasuta females are attracted to volatiles emitted by $H$. hampei immature stages but not to volatiles from adults [5]. In this study, we found that extracts from immature stages and adults of $H$. hampei influenced the locomotory behavior of this parasitoid species. Porops nasuta females searched patches more intensively where host products were present than in patches where host products were lacking. Parasitoids spent only a short time on patches without host product extracts before walking away.

In the present study, we found that the compounds affecting the locomotory behavior of $P$. nasuta females were extracted with three different solvents. However, we do not know whether the same compounds occur in the different

Table 1. Locomotory Activity of $P$. nasuta Females in Patches Treated with Hexanic Extracts from CBB Adults, Immature Stages or Hexane Control. Values are Mean $\pm \mathrm{SE}$

\begin{tabular}{|l|l|l|l|}
\hline \multicolumn{1}{|c|}{ Parameter } & \multicolumn{1}{|c|}{ Adult extract } & \multicolumn{1}{c|}{ Treatment Immature extract } & \multicolumn{1}{c|}{ Control } \\
\hline Residence time $(\mathrm{s})$ & $31.14 \pm 7.04 \mathrm{a}$ & $48.53 \pm 13.50 \mathrm{a}$ & $5.97 \pm 1.72 \mathrm{~b}$ \\
Distanced moved $(\mathrm{cm})$ & $20.29 \pm 4.09 \mathrm{a}$ & $19.81 \pm 5.55 \mathrm{a}$ & $1.47 \pm 0.27 \mathrm{~b}$ \\
Velocity $(\mathrm{cm} / \mathrm{s})$ & $0.91 \pm 0.05 \mathrm{a}$ & $0.67 \pm 0.05 \mathrm{~b}$ & $0.88 \pm 0.03 \mathrm{a}$ \\
Absolute turn angle $\left({ }^{\circ}\right)$ & $23.88 \pm 1.45 \mathrm{a}$ & $23.54 \pm 2.48 \mathrm{a}$ & $15.34 \pm 1.53 \mathrm{~b}$ \\
Absolute angular velocity $(\%)$ & $114.32 \pm 6.40 \mathrm{a}$ & $108.37 \pm 10.18 \mathrm{ab}$ & $76.54 \pm 7.59 \mathrm{~b}$ \\
Absolute meander $(\% \mathrm{~cm})$ & $281.97 \pm 24.61 \mathrm{a}$ & $317.26 \pm 46.65 \mathrm{a}$ & $167.89 \pm 15.98 \mathrm{~b}$ \\
\hline
\end{tabular}

Similar letters within a row indicate not significant difference $(\mathrm{P}<0.05$, Tukey HSD test $)$

Table 2. Locomotory Activity of P. nasuta Females in Patches Treated with Acetonic Extracts from CBB Adults, Immature Stages or Acetone Control. Values are Mean $\pm \mathrm{SE}$

\begin{tabular}{|l|l|l|l|}
\hline \multicolumn{1}{|c|}{ Parameter } & \multicolumn{1}{|c|}{ Adult extract } & Treatment Immature extract & \multicolumn{1}{c|}{ Control } \\
\hline \hline Residence time $(\mathrm{s})$ & $12.80 \pm 2.67 \mathrm{a}$ & $28.47 \pm 7.52 \mathrm{a}$ & $3.31 \pm 0.71 \mathrm{~b}$ \\
Distanced moved $(\mathrm{cm})$ & $7.42 \pm 1.63 \mathrm{a}$ & $16.25 \pm 3.23 \mathrm{a}$ & $3.83 \pm 1.13 \mathrm{~b}$ \\
Velocity $(\mathrm{cm} / \mathrm{s})$ & $0.96 \pm 0.07 \mathrm{a}$ & $0.64 \pm 0.04 \mathrm{~b}$ & $0.85 \pm 0.06 \mathrm{a}$ \\
Absolute turn angle $\left({ }^{\circ}\right)$ & $32.75 \pm 3.67 \mathrm{a}$ & $31.22 \pm 2.29 \mathrm{a}$ & $23.07 \pm 2.57 \mathrm{~b}$ \\
Absolute angular velocity $(\% / \mathrm{s})$ & $151.39 \pm 16.49 \mathrm{a}$ & $143.53 \pm 9.95 \mathrm{ab}$ & $102.25 \pm 9.12 \mathrm{~b}$ \\
Absolute meander $(\% \mathrm{~cm})$ & $365.67 \pm 59.27 \mathrm{a}$ & $412.75 \pm 42.99 \mathrm{a}$ & $190.22 \pm 27.51 \mathrm{~b}$ \\
\hline
\end{tabular}

Similar letters within a row indicate not significant difference $(\mathrm{P}<0.05$, Tukey HSD test $)$

Table 3. Locomotory Activity of $P$. nasuta Females in Patches Treated with Methanolic Extracts from CBB Adults, Immature Stages or Methanol Control. Values are Mean \pm SE

\begin{tabular}{|l|l|l|}
\hline \multicolumn{1}{|c|}{ Parameter } & \multicolumn{1}{c|}{ Adult extract } & Treatment Immature extract \\
\hline \hline Residence time $(\mathrm{s})$ & $18.22 \pm 6.13 \mathrm{a}$ & $62.66 \pm 14.70 \mathrm{a}$ \\
Distanced moved $(\mathrm{cm})$ & $7.56 \pm 2.65 \mathrm{a}$ & $22.03 \pm 5.05 \mathrm{a}$ \\
Velocity $(\mathrm{cm} / \mathrm{s})$ & $0.98 \pm 0.12 \mathrm{a}$ & $0.61 \pm 0.05 \mathrm{~b}$ \\
Absolute turn angle $\left({ }^{\circ}\right)$ & $33.06 \pm 4.37 \mathrm{a}$ & $32.27 \pm 1.92 \mathrm{a}$ \\
Absolute angular velocity $(\%)$ & $147.05 \pm 18.18 \mathrm{a}$ & $144.49 \pm 7.23 \mathrm{ab}$ \\
Absolute meander $(\% \mathrm{~cm})$ & $328.09 \pm 72.76 \mathrm{a}$ & $397.17 \pm 38.14 \mathrm{a}$ \\
\hline
\end{tabular}

Similar letters within a row indicate not significant difference $(\mathrm{P}<0.05$, Tukey HSD test) 


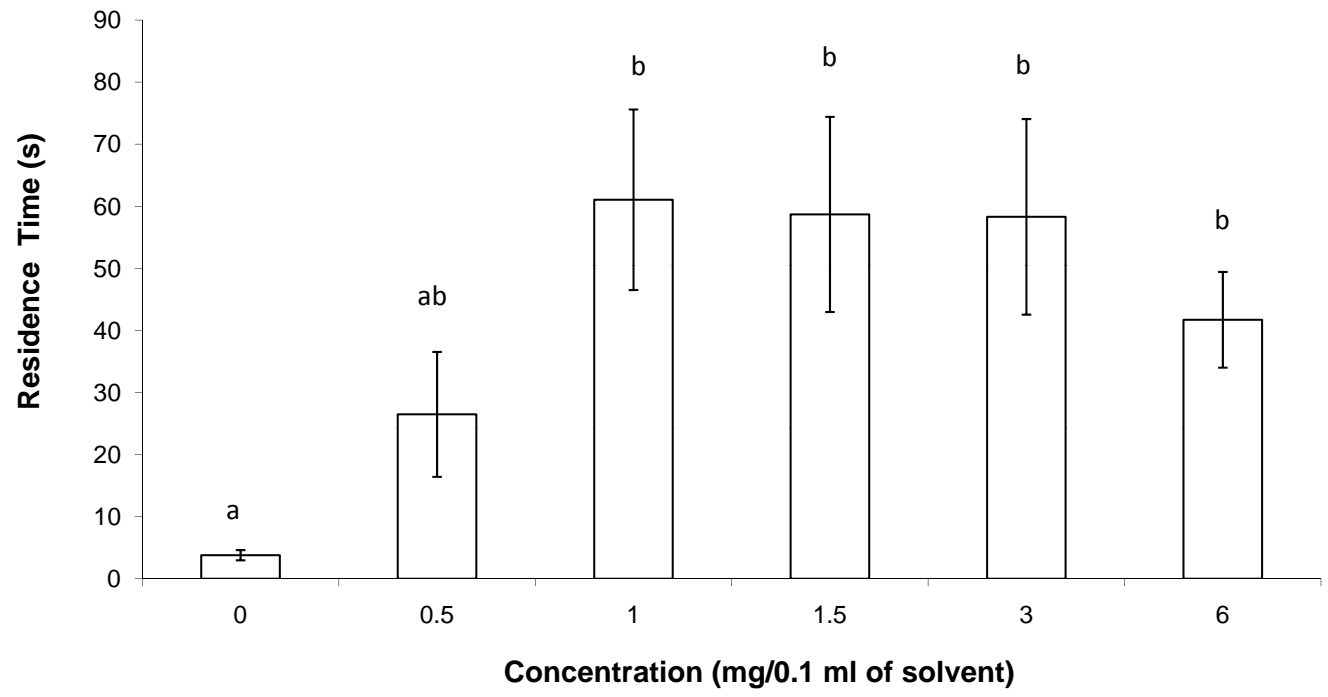

Fig. (2). Behavioral response of $P$. nasuta females to different concentrations of methanol extracts from immature stages of $H$. hampei. Bars with the same letter are not statistical different from each other, $\mathrm{P}<0.05$ (Tukey HSD). Values are mean \pm SE.

solvents or whether $P$. nasuta responded to different compounds in each one of the extracts. Preliminary gas chromatography analyses of extracts on non-polar column showed that 15,13 , and 10 compounds occur in methanol, acetone, and hexane extracts, respectively (Santiesteban \& Rojas unpublished data). However, only five compounds are common to the different extracts: 2-chlorocyclohexanol, caffeine, Z-6pentadecen-1-ol, 2-dodecanone, and an un-identified alcohol. Also, our preliminary chemical analyses of extracts showed that none of the compounds identified in extracts of adults, except caffeine, are present in immature extracts. Hexane and acetone extracts of immature stages contain mainly hydrocarbons, while methanol extract contains esters, although two hydrocarbons occur in the three types of extracts. Several species of parasitoids use cuticular hydrocarbons from hosts as contact kairomones during host location behavior [8-10]. However, whether cuticular hydrocarbons from $H$. hampei influence the locomotory behavior of $P$. nasuta females remains to be investigated. Caffeine is possibly a contaminant from coffee berries.

The fact that compounds that affect the locomotory behavior of $P$. nasuta were extracted with solvents of different polarity suggests that polar and non-polar compounds may mediate wasp arrestment on host extracts. Previous chemical studies have showed that both polar and non-polar compounds can act as behaviorally active cues responsible for inducing wasp arrestment behavior [11-13]. For example, assays performed with polar and non-polar extracts showed that the parasitoid Melittobia digitata Dahms responded strongly to hexane extract of host by-products, indicating that the nature of the kairomones is mainly non-polar soluble [12]. Likewise, it has been found that hexane extracts of $\mathrm{He}$ liothis virescens (Fabricius) frass affected the behavior of the female fly Eucelatoria bryani Sabrosky, however acetone, ethanol and water extracts from frass were inactive [13]. In contrast, females of the tachinid fly E. japonica exhibited area-restricted searching with methanolic extracts of the host's frass but not with acetone, ether, and hexane extracts [11].
Our studies clearly showed that contact chemical cues from host (this study) and host by-products [6] affected the behavior of $P$. nasuta females. However, whether the compounds present in the immature and adult extracts that elicited female arrestment behavior are the same as those present in the dust/frass extracts remains to be investigated. Our previous study showed that compounds from dust/frass of $H$. hampei that affect the locomotory behavior of $P$. nasuta were extracted with hexane, acetone and methanol [6]. However, females remained longer on the patch treated with methanol extracts than on patches treated with acetone and hexane extracts. Telenomus remus wasps were arrested after contacting a kairomone extracted from host eggs and from whole bodies of adult male or female moths [14]. The compound 13-methylhentriacontane used as a kairomone for the parasitoid Microplitis croceipes Cresson was found in the frass, larvae, saliva, and hemolymph of its host Helicoverpa zea (Boddie) [13].

\section{CONCLUSIONS}

In conclusion, we have shown that extracts from immatures and adults of $H$. hampei elicited arrestment behavior in $P$. nasuta females. Area-restricted searching activity increased with the concentration of host extracts. The fact that extracts obtained with solvents of different polarity were active suggests that both polar and non-polar compounds are involved in the arrestment of $P$. nasuta females. Studies are underway to identify the biologically active compounds present in the host and host by-product extracts that are responsible for inducing arrestment in $P$. nasuta females.

\section{ACKNOWLEDGEMENTS}

The authors thank to Juan F. Barrera for his encouragement during the course of this study, and Armando Virgen and Javier Valle-Mora for technical assistance and for statistical assistance, respectively. Julian Flavell corrected the English text. This study was supported by the Consejo Nacional de Ciencia y Tecnología (Mexico) through grant 40338Q to JCR and a graduate scholarship to P. Ch.-A. 


\section{CONFLICT OF INTEREST}

None declared.

\section{REFERENCES}

Barrera JF. Coffee pests and their management, In: Capinera JL, Ed. Encyclopedia of entomology. $2^{\text {nd }}$ ed. Dordrecht: Springer 2008; pp. 961-98.

[2] Jaramillo J, Borgemeister C, Baker P. Coffee berry borer Hypothenemus hampei (Coleoptera: Curculionidae): searching for suitable control strategies. Bull Entomol Res 2006; 96: 223-33.

[3] Morehead SA, Feener DH Jr. Visual and chemical cues used in host location and acceptance by a dipteran parasitoid. J Insect Behav 2000; 13: 613-25.

[4] Godfray HCJ. Parasitoids behavioral and evolutionary ecology. USA: Princeton University Press 1994.

[5] Chiu-Alvarado MP, Barrera JF, Rojas JC. Attraction of Prorops nasuta, a parasitoid of the coffee berry borer, to host-associated olfactory cues. Ann Entomol Soc Am 2009; 102: 166-71.

[6] Chiu-Alvarado MP, Valle-Mora J, Rojas JC. Chemical cues from the coffee berry borer influence the locomotory behavior of its bethylid parasitoids. Bull Entomol Res 2010; 100: 707-14.

[7] Chiu-Alvarado MP, Rojas JC. Behavioral responses of bethylid parasitoid species of the coffee berry borer to chemical cues from host and non-host dust/frass. BioControl 2011; 56: 45-53
Jones RL, Lewis WJ, Bowman MC, Beroza M, Bierl BA. Hostseeking stimulant for parasite of corn earworm: isolation, identification and synthesis. Science 1971; 173: 842-3.

[9] Rutledge CE. A survey of identified kairomones and synomones used by insect parasitoids to locate and accept their hosts. Chemoecology 1996; 7: 121-31.

[10] Colazza S, Aquila G, De Pasquale C, Peri R, Millar JC. The egg parasitoid Trissolcus basalis uses n-nonadecane, a cuticular hydrocarbon from its stink bug host Nezara viridula, to discriminate between female and male hosts. J Chem Ecol 2007; 33: 1405-20.

[11] Tanaka C, Kainoh Y, Honda H. Host frass as arrestant chemicals in locating host Mythumma separata by the tachinid fly Exorista japonica. Entomol Exp Appl 2001; 100: 173-8.

[12] González JM, Cusumano A, Williams HJ, Colazza S, Vinson SB. Behavioral and chemical investigations of contact kairomones re leased by the mud dauber wasp Trypoxylon politum, a host of the parasitoid Melittobia digitata. J Chem Ecol 2011; 37: 629-39.

[13] Nettles W Jr. Contact stimulants from Heliothis virescens that influence the behavior of females of the tachinid, Eucelatoria bryani. J Chem Ecol 1982; 8: 1183-91.

[14] Gazit Y, Lewis WJ, Tumlinson JH. Arrestment of Telenomus remus (Hymenoptera: Scelionidae) by a kairomone associated with eggs of its host, Spodoptera frugiperda (Lepidoptera: Noctuidae). Biol Control 1996; 6: 283-90.

(C) Chiu-Alvarado et al.; Licensee Bentham Open.

This is an open access article licensed under the terms of the Creative Commons Attribution Non-Commercial License (http://creativecommons.org/ licenses/by-nc/3.0/), which permits unrestricted, non-commercial use, distribution and reproduction in any medium, provided the work is properly cited. 